\section{Edycaçäa

\section{Editor}

Maria Inês Côrte Vitoria PUCRS, RS, Brasil

\section{Editor Executivo}

Pricila Kohls dos Santos PUCRS, RS, Brasil

\section{Equipe Editorial}

Rosa Maria Rigo PUCRS, RS, Brasil

Carla Spagnolo PUCRS, RS, Brasil Martha Luci Sozo PUCRS, RS, Brasil Dirce Hechler Herbertz PUCRS, RS, Brasil

\section{ISSN 2179-8435}

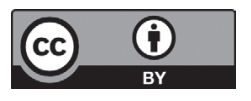

Este artigo está licenciado sob forma de uma licença Creative Commons Atribuição 4.0 Internacional, que permite uso irrestrito, distribuiçăo e reprodução seja corretamente citad http://creativecommons.org/licenses/by/4.0/deed.pt_BP

\title{
Estado de conhecimento da pesquisa acadêmica sobre 0 aluno adulto da educação de jovens e adultos (2011-2014)
}

\author{
State of Knowledge in the Academic Research about the Adult Learners \\ in the Young and Adult Education (2011-2014)
}

\section{Fernanda de Brito Kulmann Conzattia} Tárcia Rita Davogliob

RESUMO: Esta pesquisa bibliográfica objetivou construir o estado de conhecimento das produções acadêmicas realizadas com alunos adultos da Educação de Jovens e Adultos (EJA), disponíveis no Banco de Teses da CAPES e na Biblioteca Digital Brasileira de Teses e Dissertações (BDTD) do Instituto Brasileiro de Informação em Ciência e Tecnologia (IBICT), entre 2011 e 2014, visando responder a questão norteadora "O que as pesquisas têm revelado sobre o aluno adulto da Educação de Jovens e Adultos?". Foram definidos os descritores “educação de jovens e adultos" e "adultos" para as buscas iniciais, filtradas pelo ano e aplicados critérios de inclusão a partir da leitura flutuante do material recuperado. O corpus textual selecionado, composto por 12 publicações, foi sistematizado por data da defesa, título, autor, palavras-chave e linha de pesquisa e categorizado por temáticas, originando uma categoria específica. A posterior análise de conteúdo apontou que a maioria do público adulto da EJA é proveniente do campo e periferia das cidades, com histórias de luta pela subsistência, dificuldades de acesso e permanência na escola, além de trabalhar durante a infância e a adolescência. A busca pela transformação e pela afirmação de seus direitos na sociedade mostrou ser um dos motivos que os impulsionam a retornar aos bancos escolares. Apesar das buscas limitadas a dois bancos de dados, constatamos por meio deste estudo que as pesquisas voltadas ao público adulto aluno da EJA ainda são reduzidas, demandando novas perspectivas que extrapolem o entendimento da EJA como uma modalidade compensatória de Educação.

Palavras-chave: estado de conhecimento; educação de jovens e adultos; aluno; adulto; banco de teses.

a Mestranda do Programa de Pós-Graduação em Educação da Faculdade de Educação da Pontifícia Universidade Católica do Rio Grande do Sul. Bolsista da Comissão de Aperfeiçoamento de Pessoal de Nível Superior (CAPES)/ Programa de Excelência Acadêmica (PROEX).

b Doutora em Psicologia. Professora colaboradora na Faculdade de Educação da Pontifícia Universidade Católica do Rio Grande do Sul e bolsista do Programa Nacional de Pós-Doutorado/CAPES - Edital DOCFIX da Fundação de Amparo à Pesquisa do Estado do Rio Grande do Sul (FAPERGS). Coordenadora do grupo de pesquisa Psicologia Aplicada: Pessoa e Contextos. 
ABSTRACT: This bibliographic research aimed to construct the state of knowledge of the academic productions accomplished with adult learners of the Young and Adult Education (EJA), available in the Thesis Bank of CAPES and in the Brazilian Digital Library of Thesis and Dissertations (BDTD) of the Brazilian Institute of Information in Science and Technology (IBICT), between 2011 and 2014, aiming to respond the guiding question "What does the researches has revealed about the adult learners in the Young and Adult Education?". Has been defined the descriptors "education of young and adult" and "adult" to the initial searches, filtered by year, applied inclusion criteria from the initial reading of the recovered material. The textual corpus selected, composed by 12 publications, was systematized by defense date, title, author, keywords and research line and categorized by themes, causing a particular category. The further content analysis pointed that the majority of the adult public of EJA is from the countryside and suburb of the cities, with an history of subsistence fight, difficulties of access and permanence in school, besides working during childhood and adolescence. The search for transformation and affirmation of their rights in society shows to be one of the motive that boosted them to return to the school seats. Although the limited searches to two databases, we found through this study that the researches focused on the public of educating adult of EJA are still reduced and demands new perspectives that go beyond the understanding of EJA as a compensatory mode of Education.

Keywords: state of knowledge; youth and adult education; student; adult; theses bank.

\section{Apresentação}

s produções e estudos científicos voltados à Educação de Jovens e Adultos (EJA) no Brasil ainda são incipientes se comparadas a outras temáticas na Educação, conforme Haddad (2011). Provavelmente um dos motivos que justificam tal situação seja a forma como a EJA e, mais especificamente, a Educação de Adultos (EA) se constituiu ao longo da história.

Relegada a um segundo plano, tanto nas políticas educacionais quanto no investimento social e educacional para com os jovens e adultos que foram marginalizados do processo de escolarização, a EJA foi marcada pela inexistência de políticas efetivas para com este público, sendo o resultado de campanhas descontínuas e de interesses políticos desenvolvimentistas e moralistas. Desse modo, a própria EJA não atraiu para si o foco da pesquisa acadêmica, a não ser recentemente.

Embora não se discuta a relevância de abordar a temática como objeto da ciência, um estudo realizado por Haddad (2002) sobre a produção científica produzida no Brasil, no período entre 1986 e 1998, revelou que menos de 3\% das dissertações e teses da área da Educação voltou-se para a EJA. Contudo, em 1998, Soares (2011) liderou um levantamento acerca das produções do Grupo de Trabalho (GT) "Educação de Jovens e Adultos", também 
nomeado como "Educação de Pessoas Jovens e Adultas", da Associação Nacional de Pós-Graduação e Pesquisa em Educação (ANPED). A análise desse levantamento, restrita ao período entre 1998 e 2008, constatou que houve um incremento significativo das produções sobre a temática, sobretudo aquelas no âmbito dos programas de pósgraduação em Educação. Porém, não se encontrou na literatura recente outros levantamentos dessa natureza. Diante disso, consideramos relevante que novos estudos sobre o Estado do Conhecimento e/ou Estado da Arte sejam realizados para verificar e analisar o que está sendo produzido acerca da temática EJA, de modo a fomentar o debate e a reflexão.

Para tanto, esclarecemos a escolha pelo Estado de Conhecimento em contraposição ao Estado da Arte. O Estado de Conhecimento, segundo Romanowski e Ens (2006,) diz respeito ao levantamento e análise de produções de apenas uma base de dados sobre o tema estudado, enquanto que o Estado da Arte abrange a totalidade de uma área de conhecimento nas diversas fontes, como por exemplo, teses, dissertações, periódicos e demais publicações.

Ainda, de acordo com Morosini e Fernandes (2014, p. 155), “[...] estado de conhecimento é identificação, registro, categorização que levem à reflexão e síntese sobre uma determinada área, em um determinado espaço de tempo [...]". Portanto, construir o Estado de Conhecimento de um campo temático a ser investigado possibilita constatar e analisar o que foi produzido, com o objetivo de consolidar a produção científica a ser tecida pelo pesquisador, de modo a torná-la mais qualificada e fundamentada.

Nesse sentido, o presente estudo objetivou construir o Estado de Conhecimento das produções acadêmicas (dissertações e teses) no âmbito dos alunos adultos da EJA, por meio de consulta ao Banco de Teses da Comissão de Aperfeiçoamento de Pessoal de Nível Superior (CAPES) e na Biblioteca Digital Brasileira de Teses e Dissertações (BDTD) do Instituto Brasileiro de Informação em Ciência e Tecnologia (IBICT), no período compreendido entre 2011 e 2014, visando responder a questão norteadora "O que as pesquisas têm revelado sobre o aluno adulto da Educação de Jovens e Adultos?”.

\section{0 caminho metodológico percorrido}

Embora a intenção inicial desta pesquisa bibliográfica fosse localizar os trabalhos produzidos nos últimos cinco anos no Banco de Teses da CAPES e da BDTD/IBICT, justifica-se a inclusão do período entre 2011 e 2014, considerando que as buscas pelos anos 2010 e 2015 não evidenciaram resultados. No Banco de Tese da CAPES foram disponibilizados os dados referentes a 2011 e 2012 e na BDTD/IBICT, entre 2011 e 2014. Portanto, as buscas realizadas no Banco de Teses da CAPES concentraram-se nos anos de 2011 e 2012 e na BDTD/IBICT, entre 2013 e 2014. 
O percurso metodológico consistiu na definição dos descritores para as buscas e o refinamento da pesquisa; leitura flutuante das dissertações e teses resultantes da busca; estabelecimento de critérios de inclusão para a seleção do corpus textual; sistematização do corpus selecionado, a partir dos seguintes elementos: título do trabalho, autor, objetivo(s), caracterização dos participantes da pesquisa; metodologia, resultado(s) e conclusão(ões) e análise de conteúdo do material selecionado (MORAES, 1999).

Os descritores definidos para a busca foram "educação de jovens e adultos" e "adultos", utilizando o filtro "data da defesa". No Banco de Teses da CAPES foram utilizados os filtros "palavra-chave: educação de jovens e adultos", "resumo: adultos" e "data da defesa: 2011; 2012". Na BDTD/IBICT foram utilizados os filtros "País: Brasil", "Idioma: Português", "Resumo: adultos", “Assunto: educação de jovens e adultos", ano de defesa: "2013 a 2014".

Segundo Oliveira et al. (2003), toda a análise de conteúdo é precedida pela leitura flutuante dos textos, num processo recursivo de retomadas com o fim de apropriar-se do texto para apreender os principais conceitos ou temas abordados. Portanto, esta etapa configurou-se como um elemento fundamental para a seleção do corpus de análise.

Ainda sobre a análise de conteúdo, Moraes (1999) afirma que esta metodologia de análise de dados requer a apreensão dos significados emergidos a partir da leitura realizada, para além de uma leitura comum. Seria um processo de impregnação do pesquisador com o material de análise em que diversos sentidos e/ou significados poderão variar de um leitor para o outro. "De certo modo a análise de conteúdo, é uma interpretação pessoal por parte do pesquisador com relação à percepção que tem dos dados. Não é possível uma leitura neutra. Toda leitura se constitui numa interpretação." (MORAES, 1999, p. 3).

Os seguintes critérios de inclusão foram adotados para a seleção do corpus de análise no Banco de Teses da CAPES: (a) Dissertações e teses produzidas na área de conhecimento Educação; (b) Alunos adultos da EJA como público-alvo da pesquisa, com enfoque nas suas características e peculiaridades, bem como os sentidos/significados atribuídos por estes alunos ao processo de escolarização vivenciado na Educação de Jovens e Adultos; (c) Pesquisas de abordagem qualitativa, utilizando os seguintes instrumentos de coleta de dados: entrevistas semiestruturadas e/ou abertas, observação e/ou análise documental.

Ressalta-se que o critério "Dissertações e teses produzidas na área de conhecimento Educação" não foi adotado para a seleção do corpus dos trabalhos pesquisados na BDTD, tendo em vista que houve um número reduzido de pesquisas envolvendo o sujeito adulto aluno da EJA e, principalmente, porque um dos trabalhos produzidos na área "Letras" foi bastante representativo para o enfoque dado a este trabalho. No entanto, todos os demais critérios foram adotados.

As dissertações e teses selecionadas para análise foram aquelas que tinham como objetivo enfocar o(s) aluno(s) adulto(s) da Educação de Jovens e Adultos, com a finalidade de caracterizá-lo(s) em suas especificidades, bem como 
analisar os impactos produzidos na(s) sua(s) vida(s) a partir do percurso trilhado nesta modalidade de ensino. A partir desta etapa metodológica, procedeu-se à preparação, unitarização, categorização, descrição e interpretação do corpus de análise selecionado (MORAES, 1999). Conforme o referido autor, estes períodos constituem uma das diversas formas de se realizar a descrição do processo da análise de conteúdo.

A preparação diz respeito à leitura dos materiais devendo ser elencados quais deles estão de acordo com o objetivo do estudo. A partir deste momento, uma codificação dos materiais deve ser feita para que possam ser identificados. A segunda etapa, a unitarização, envolve a definição das unidades de análise, ou seja, a unidade de conteúdo a ser classificada posteriormente. A categorização é o agrupamento dos dados levando em consideração as partes comuns que os definem. Diferentes critérios poderão ser usados para a sua definição. Neste estudo, optamos pela categorização temática, por considerá-la mais apropriada.

Quanto à descrição ela abarca uma "comunicação" (MORAES, 1999) dos dados e requer a produção de uma explicação sobre cada uma das categorias, de modo a expressar o seu significado ao leitor. E, por fim, a interpretação, que consiste na exploração dos significados do corpus, permitindo um movimento cíclico de "teorização, interpretação e compreensão" (idem, p. 10).

\section{Sistematização dos resultados e processo de categorização}

\subsection{Banco de Teses da CAPES}

O Banco de Teses da CAPES (<http://bancodeteses.capes.gov.br>) reúne as produções acadêmicas (teses e dissertações) desenvolvidas nos programas de pós-graduação (PPG) do país, disponibilizando as referências e resumos das pesquisas. Apesar da proposta do referido Banco disponibilizar as produções defendidas anualmente nos PPG do Brasil, atualmente somente poderão ser consultadas os estudos entre os anos de 2011 e 2012.

A pesquisa no Banco de Teses da CAPES apontou um total de 140 trabalhos para o descritor "educação de jovens e adultos" e o filtro "data da defesa": "2011" e "2012", respectivamente, distribuídos nos níveis de Mestrado Acadêmico (MA), Mestrado Profissionalizante (MP) e Doutorado (D). Em 2011 foram registradas 60 dissertações (53 no nível de MA e 07 no MP) e 12 teses, e no ano de 2012, 60 dissertações (55 no MA e 05 no MP) e 08 teses.

Acrescentando-se o descritor "adultos" para o filtro "resumo" foram encontrados um total de 129 trabalhos, sendo 65 no ano de 2011 e 64 no ano de 2012. Para o ano de 2011, a busca resultou em 54 dissertações (47 no nível de MA e 07 no MP) e 11 teses. Em 2012, foram 57 dissertações (52 no nível de MA e 05 no MP) e 07 teses, distribuídas em diversas áreas de conhecimento, conforme o Gráfico 1. 
Gráfico 1. Áreas de conhecimento da produção acadêmica acerca dos sujeitos adultos da EJA (Banco de Teses/CAPES, 2011-2012)

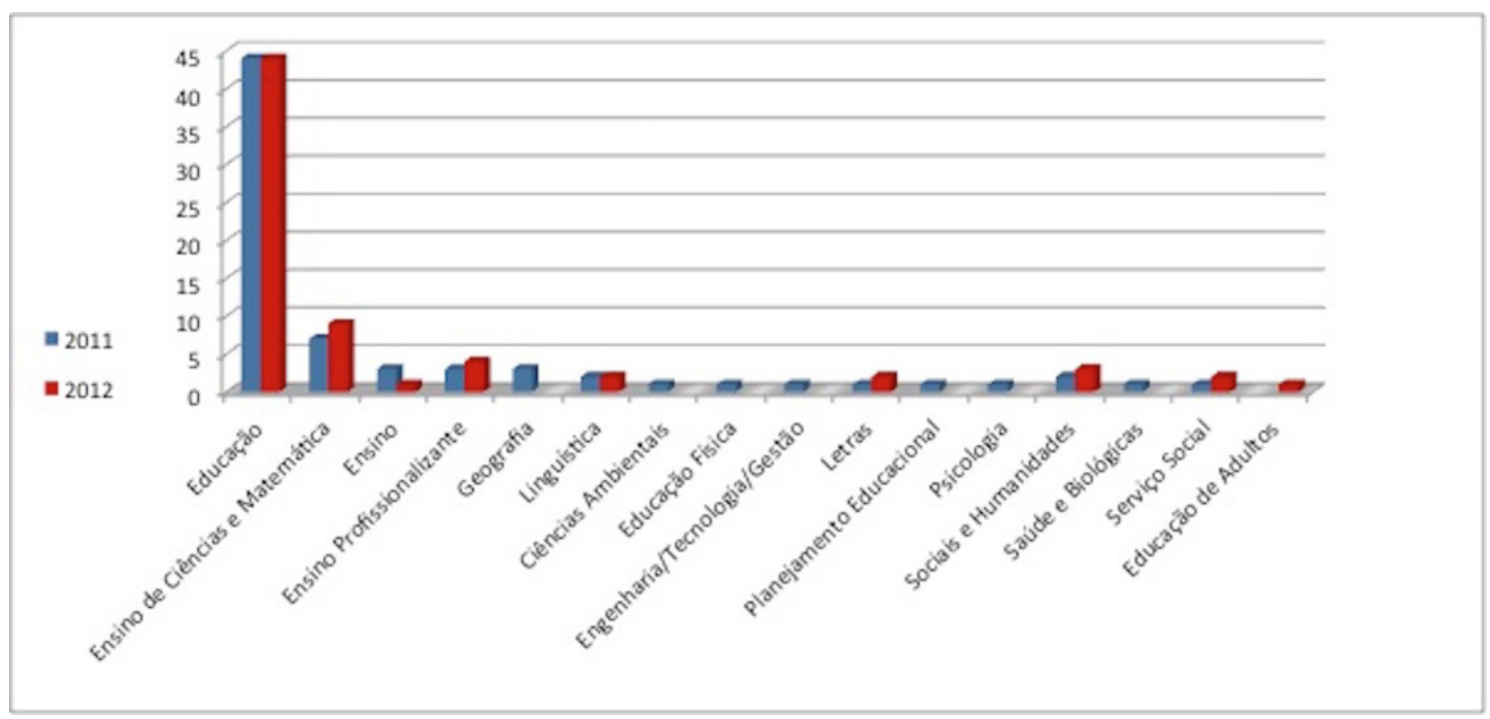

Fonte: Elaborado pelas autoras, 2015

A partir destes dados verificamos que o maior número de produções acadêmicas sobre o aluno adulto da EJA esteve centrado no âmbito do Mestrado (111 dissertações) num total de 129 pesquisas realizadas na pós-graduação. Constatamos que a maior parte das pesquisas concentrou-se na área da Educação ( 88 trabalhos), embora os estudos sobre a EJA sejam produzidos também em outras áreas de conhecimento, o que possibilita um olhar multidisciplinar acerca desta temática (Serviço Social, Linguística, Psicologia, Saúde e Biológicas, Sociais e Humanidades, Engenharia/Tecnologia/Gestão, Ciências Ambientais, por exemplo).

A partir dos critérios de inclusão adotados para o presente estudo, foram selecionados 40 trabalhos no ano de 2011 e 42 no ano de 2012 pertencentes à área "Educação", totalizando 82 trabalhos. Por meio da leitura flutuante do título, palavras-chave, resumo e linha de pesquisa, foram retidos 09 trabalhos, 04 no ano de 2011 e 05 em 2012, de acordo com o Quadro 1. 
Quadro 1. Sistematização do corpus de análise proveniente do Banco de Teses CAPES no período de 2011-2012

\begin{tabular}{|c|c|c|c|c|}
\hline $\begin{array}{l}\text { Data da } \\
\text { defesa }\end{array}$ & Título & Autor & Palavras-chave & Linha de Pesquisa \\
\hline \multirow{4}{*}{2011} & $\begin{array}{l}\text { Formação Escolarizada de Sujeitos Alunos } \\
\text { na Educação de Jovens e Adultos - EJA, em } \\
\text { Porto Velho }\end{array}$ & $\begin{array}{l}\text { Maria do Socorro D. } \\
\text { Loura }\end{array}$ & $\begin{array}{l}\text { EJA; educação; } \\
\text { linguagem }\end{array}$ & $\begin{array}{l}\text { Formação do professor, trabalho } \\
\text { docente e práticas pedagógicas }\end{array}$ \\
\hline & $\begin{array}{l}\text { Educação de Jovens e Adultos: Perspectivas e } \\
\text { evasão no município de Cáceres - MT }\end{array}$ & Pedro José de Lara & $\begin{array}{l}\text { EJA; evasão } \\
\text { escolar }\end{array}$ & $\begin{array}{l}\text { Formação e prática pedagógica } \\
\text { do profissional docente }\end{array}$ \\
\hline & $\begin{array}{l}\text { Da Escolarização à reinvenção de si } \\
\text { os sentidos da aprendizagem para o aluno } \\
\text { da EJA }\end{array}$ & Liliam C. Caldeira & $\begin{array}{l}\text { EJA; } \\
\text { aprendizagem; } \\
\text { sentidos }\end{array}$ & Educação e trabalho \\
\hline & $\begin{array}{l}\text { Trajetórias de exclusão e novas expectativas: } \\
\text { um estudo sobre jovens e adultos em } \\
\text { processo de alfabetização no município de } \\
\text { Araraquara - SP }\end{array}$ & Mônica Pereira & $\begin{array}{l}\text { alfabetização de } \\
\text { adultos; EJA }\end{array}$ & $\begin{array}{l}\text { História, filosofia e sociologia } \\
\text { da educação }\end{array}$ \\
\hline \multirow{4}{*}{2012} & $\begin{array}{l}\text { Sentidos da Educação de jovens e Adultos } \\
\text { na perspectiva do aluno idoso }\end{array}$ & $\begin{array}{l}\text { Roberta P. R. M. } \\
\text { Cortes }\end{array}$ & $\begin{array}{l}\text { EJA; idoso; velhice; } \\
\text { identidade }\end{array}$ & $\begin{array}{l}\text { Instituições educacionais e suas } \\
\text { práticas pedagógicas }\end{array}$ \\
\hline & $\begin{array}{l}\text { A EJA em minha vida: Trajetórias sociais de } \\
\text { egressos/as da Educação de jovens e adultos } \\
\text { no município de Palhoça (SC) }\end{array}$ & $\begin{array}{l}\text { Sheyla Aparecida } \\
\text { Pereira }\end{array}$ & $\begin{array}{l}\text { EJA; construção da } \\
\text { escrita; ensino }\end{array}$ & Processos de ensinar e aprender \\
\hline & $\begin{array}{l}\text { Alunos idosos na EJA: A importância da } \\
\text { família e dos grupos de convivência no } \\
\text { processo de escolarização }\end{array}$ & $\begin{array}{l}\text { Cláudia Elizângela } \\
\text { B. S. Almeida }\end{array}$ & idoso; EJA; família & $\begin{array}{l}\text { Instituições educacionais e suas } \\
\text { práticas pedagógicas }\end{array}$ \\
\hline & $\begin{array}{l}\text { Educação de jovens e adultos: um estudo } \\
\text { sobre trajetórias escolares interrompidas }\end{array}$ & $\begin{array}{l}\text { Vilson Pereira dos } \\
\text { Santos }\end{array}$ & $\begin{array}{l}\text { EJA; direito; evasão } \\
\text { escolar }\end{array}$ & Educação, sociedade e cultura \\
\hline
\end{tabular}

Fonte: Elaborado pelas autoras, 2015.

\section{Biblioteca Digital Brasileira de Teses e Dissertações/IBICT}

A Biblioteca Digital Brasileira de Teses e Dissertações (BDTD) é um banco de dados que tem por objetivo reunir, em um único portal, as teses e dissertações produzidas no país. Integra o Instituto Brasileiro de Informação 
em Ciência e Tecnologia (IBICT), sendo este um dos responsáveis em coletar os metadados (título, palavras-chave, resumo, etc) das teses e dissertações dos provedores.

A pesquisa realizada abrangeu os anos de 2013 e 2014 no sítio (<http://www.ibict.br/informacao-para-cienciatecnologia-e-inovacao\%20/biblioteca-digital-brasileira-de-teses-e-dissertacoes-bdtd $>$ ).

$\mathrm{Na}$ busca avançada foram encontrados 27 resultados sobre estudos voltados à EJA, entre os anos de $2013 \mathrm{e}$ 2014, sendo 19 dissertações (12 em 2013 e 07 em 2014) e 08 teses (05 em 2013 e 03 em 2014). Destes, somente 05 estudos retratam o sujeito aluno da EJA e apenas 04 sobre os sujeitos adultos da EJA. Todas estas pesquisas foram realizadas no nível de Mestrado e nenhuma no Doutorado.

Para fins de análise foram retidos 04 pesquisas para estudo em profundidade, como mostra o Quadro 2 , sendo subcategorizadas nos eixos temáticos: Prática Pedagógica (02 trabalhos) e Processos de ensino e aprendizagem (02).

Quadro 2. Sistematização dos trabalhos selecionados para análise oriundo da BDTD/IBICT no período de 2013-2014

\begin{tabular}{|c|c|c|c|c|}
\hline Ano & Título & Autor & Palavras-chave & Área de concentração \\
\hline 2013 & $\begin{array}{l}\text { O Diurno na educação de jovens e adultos: } \\
\text { quem são esses sujeitos? }\end{array}$ & $\begin{array}{l}\text { Andréia Cristina } \\
\text { S. Soares }\end{array}$ & $\begin{array}{l}\text { EJA; Ensino diurno; } \\
\text { Direito à educação }\end{array}$ & $\begin{array}{l}\text { Educação: Educação Inclusiva e } \\
\text { Processos Educacionais }\end{array}$ \\
\hline \multirow{3}{*}{2014} & $\begin{array}{l}\text { Cartografia de vida no trabalho educativo com } \\
\text { jovens e adultos: conversas-em-ação }\end{array}$ & $\begin{array}{l}\text { Jaqueline Dinorá } \\
\text { P. de Campos }\end{array}$ & $\begin{array}{l}\text { EJA; Subjetividade } \\
\text { e educação; Ensino- } \\
\text { Aprendizagem; } \\
\text { Educação e } \\
\text { produção de saúde }\end{array}$ & Educação: Educação em Saúde \\
\hline & $\begin{array}{l}\text { Memória e identidade do aluno da EJA em } \\
\text { relatos autobiográficos }\end{array}$ & $\begin{array}{l}\text { Adenivan M. } \\
\text { Carvalho }\end{array}$ & $\begin{array}{l}\text { EJA; Relato } \\
\text { autobiográfico; } \\
\text { Memória; Identidade; } \\
\text { Análise de conteúdo }\end{array}$ & Letras \\
\hline & $\begin{array}{l}\text { Desvelando histórias de alunas (os) } \\
\text { trabalhadoras (es) do pmea: indícios para } \\
\text { construção de uma EJA democrática e } \\
\text { dialógica. }\end{array}$ & $\begin{array}{l}\text { Rafael Domingues } \\
\text { da Silva }\end{array}$ & $\begin{array}{l}\text { Educação de Jovens } \\
\text { e Adultos; Educação } \\
\text { dialógica; PMEA; } \\
\text { Histórias de vida e de } \\
\text { Escolarização }\end{array}$ & $\begin{array}{l}\text { Educação: Saberes e Práticas } \\
\text { Educativas }\end{array}$ \\
\hline
\end{tabular}

Fonte: Elaborado pelas autoras, 2015. 
A partir da leitura completa de cada um dos 12 trabalhos realizou-se uma categorização temática, surgindo 05 subcategorias assim denominadas: Acesso, Evasão e Permanência (02 trabalhos), Alfabetização e Letramento (01), Escolarização (03), Prática Pedagógica (02) e Processo de Ensino e Aprendizagem (01).

As definições para cada uma das subcategorias foi baseada nos Thesaurus ${ }^{1}$, do Instituto Nacional de Estudos e Pesquisas Nacionais Anísio Teixeira (INEP):

1. Acesso, evasão e permanência: diversidade de aspectos socioeducacionais que impossibilitam ou garantem o acesso e a permanência de alunos na escola.

2. Alfabetização e Letramento: práticas de ensino e aprendizagem das noções elementares da leitura e escrita; práticas sociais do uso da leitura e escrita.

3. Escolarização: processo educativo formal, programado, executado e controlado por uma instituição escolar de ensino.

4. Práticas Pedagógicas: ações cotidianas do professor em sala de aula, fundamentada por suas concepções teóricas e os saberes advindos da experiência objetivando a aprendizagem dos alunos.

5. Processos de ensino e aprendizagem: estratégias utilizadas pelo professor para que os objetivos propostos pelo plano de ensino sejam atingidos, constituindo o trabalho escolar.

Desta categorização temática, emergiu a categoria "Sujeitos alunos adultos da EJA", tendo como foco o estudo sobre estes sujeitos a partir do processo educativo trilhado na modalidade da Educação de Jovens e Adultos. No entanto, esta categorização não é única, pois os trabalhos abarcam outras possibilidades de categorização, tendo em vista que os elementos que os diferenciam são bastante tênues. Ademais, conforme já mencionado anteriormente, o processo de interpretação presente na análise de conteúdo prevê a possibilidade da produção de vários significados e múltiplas interpretações sobre uma dada interpretação (MORAES, 1999).

\section{Análise e discussão dos resultados}

Para o propósito deste estudo foram selecionadas 13 publicações das bases de dados pesquisadas. No entanto, esclarecemos que, para fim de categorização temática das publicações e análise dos resultados, somente puderam ser lidos, na íntegra, 12 trabalhos, pois um deles não estava disponível na biblioteca digital da universidade em que foi realizado.

\footnotetext{
1 Segundo informações no sítio do INEP, thesaurus é uma ferramenta que integra os termos escolhidos a partir de uma estrutura conceitual previamente estabelecida com a finalidade de indexar e recuperar informações e documentos numa determinada área de conhecimento. Desta maneira, é um instrumento que facilita a busca de informações por parte dos pesquisadores.
} 
Além disso, ressaltamos a dificuldade encontrada na definição dos descritores, pois observamos que não há, via de regra, uma padronização no uso destes pelos seus autores, demandando do pesquisador mais tempo e maior número de combinações de filtros para alcançar os resultados desejados na busca. Ademais, estes descritores muitas vezes são mal empregados, não havendo qualquer relação entre as palavras-chave do trabalho e o título e/ou resumo do mesmo. Para exemplificar este aspecto quando acrescentamos ao filtro "resumo" o termo "sujeito" foram encontrados 21 registros. No entanto, destes 21 somente 02 dos 05 trabalhos que foram posteriormente selecionados apareceram usando este filtro, não sendo efetivo para a busca. Já ao usarmos o filtro "sujeito" foram encontrados 04 registros, nenhum deles apresentando relação com o objeto aqui proposto. Logo, justificou-se a realização de uma busca mais ampla dos registros por meio de 3 filtros: data da defesa, educação de jovens e adultos e adultos.

Neste sentido, Soares, Silva e Ferreira (2011) alertaram sobre dificuldades similares para o levantamento do estado da arte das pesquisas na EJA, entre o período de 1998 e 2008, no GT de EJA da ANPED. Analisando o processo de categorização feito pela ANPED dos trabalhos apresentados no referido GT, eles mencionaram o quão difícil é fazer uma categorização que abarque todas as dimensões dos trabalhos apresentados. Portanto, é necessário estabelecer critérios claros e objetivos utilizados neste processo para o aprimoramento das pesquisas futuras na EJA: “Aprofundar a compreensão sobre cada categorização é uma tarefa que pode contribuir na construção do corpo teórico de cada eixo, na revisão bibliográfica de trabalhos futuros e consequentemente no acúmulo teórico-metodológico sobre a Educação de Jovens e Adultos." (Idem, p. 42).

A categoria "Sujeitos adultos alunos da EJA", que emergiu da análise textual, englobou as pesquisas que convergiram no seguinte aspecto: todos procuraram dar voz aos alunos que frequentaram esta modalidade de ensino, valorizando as suas experiências e interpretações quanto às ações empreendidas a partir do processo de escolarização vivenciado. Os enfoques destes sujeitos apareceram também sob o prisma da exclusão e negação do direito à educação deste público; relação conflituosa entre trabalho e estudo desde a infância e as motivações de evasão, retorno e permanência na escola.

Estes "sujeitos alunos adultos da EJA" são nomeados pelos diferentes autores como "alunos, estudantes, adultos, idosos, trabalhadores, alunos", sem, contudo, adentrar na conceituação do que realmente seja sujeito. No entanto, consideramos importante explicitar, rapidamente, a concepção teórica que abarca esta categoria elencada e emergida neste trabalho sobre a noção de "sujeito".

Segundo Dias et al. (2011), não há consenso, no campo teórico, acerca do que venha a ser sujeito. De um lado, diz respeito à capacidade da pessoa tornar-se o centro da ação social e, de outro, à inserção do indivíduo na História, na cultura, na linguagem, a fim de criar a sua própria história neste contexto: o sujeito social. Deste modo, nos pareceu mais apropriado conceituá-los na perspectiva de sujeitos sociais, imersos num universo de diferenças culturais 
emergentes que suscitaram uma mudança no público das instituições escolares, até então brancos, de classe média e do sexo masculino (ibidem), provocando a emergência de novos atores sociais, intérpretes de suas próprias histórias.

As pesquisas aqui analisadas apontaram que o público adulto da EJA é proveniente, na grande maioria, do campo e da periferia das cidades, com histórias de luta pela subsistência, dificuldades de acesso e permanência na escola, além de trabalhos precários durante a infância e a adolescência. As tentativas de retomada dos estudos quando adulto implicou na dificuldade de conciliar a escola com o trabalho devido ao excesso de trabalho, à incompatibilidade entre o horário de trabalho e o escolar, o cansaço, os problemas familiares (prisão do filho, ciúme do cônjuge - no caso das mulheres entrevistadas), os problemas de saúde e as dificuldades de aprendizagem (LARA, 2011), havendo um diferencial nos motivos que fizeram com que homens e mulheres abandonassem a escola, segundo estudo de Almeida (2012): no caso das mulheres, a necessidade de aprender práticas domésticas e cuidar dos irmãos mais novos e, dos homens, a complementação da renda familiar. Constatação similar no que diz respeito à questão de gênero também pode ser verificada na pesquisa de Soares (2013). As mulheres tiveram a trajetória escolar interrompida ou negada quando se tornaram mães tomando a decisão de cuidar dos filhos para depois cuidarem-se.

Carvalho (2014) também aponta o "casamento arranjado" como um dos motivos pelos quais as mulheres não puderam iniciar ou prosseguir o percurso escolar. A proibição ao ensino das mulheres também foi apontado por Campos (2014) e Silva (2014), o que demonstra que a exclusão das mulheres do processo educativo permaneceu mesmo após a universalização do acesso de todos à educação.

Conforme Caldeira (2011), a exclusão social e escolar destes sujeitos foi motivada pelo trabalho, sobrevivência, falta de escolas no meio rural, cansaço para conciliar escola e trabalho, preconceito da família quanto à escolarização das mulheres e a supervalorização do saber erudito da escola. Ainda, a pesquisadora concluiu que o ato de aprender, pelos alunos, está ligado a um caminho de mudanças e de transformações de diferentes ordens e de socialização. O aluno adulto que busca a EJA vê nesta modalidade a possibilidade de construir uma nova imagem de si, muito mais do que recuperação do tempo perdido ou de melhorias na sua condição financeira.

Estudos de Campos (2014), com alguns idosos que retomaram o seu processo de escolarização em um Núcleo Educativo de Educação de Jovens e Adultos (NEEJA) não presencial, também apontaram outros fatores para o abandono escolar deste público: comportamento desviante do padrão da escola, repetências, dificuldades de aprendizagem, transtornos mentais, privação parcial de liberdade e em medida protetiva ou socioeducativa, exclusão pela própria escola, falta de escola no meio rural.

Outro enfoque do sujeito retratado nas pesquisas foi os sentidos da retomada e permanência dos estudos na EJA, motivada por diferentes razões: necessidade de inserção no mercado de trabalho (maior qualificação); maiores oportunidades para adquirir uma condição de cidadania e inclusão sociocultural; o acesso ao conhecimento vinculado 
na escola; a busca de (re)construção de si; o desejo de certificação; a socialização; viver melhor, permitindo realizar outras leituras de mundo; enfrentamento de desafios; aprender a ler e a escrever; a cobrança dos filhos para retornar à escola; tirar uma carteira de habilitação (CALDEIRA, 2011). Ainda, segundo estudo realizado por Lara (2011), com 20 alunos que evadiram a EJA, 65\% dos entrevistados disse que um dos motivos para voltar a estudar esteve relacionado ao trabalho, $30 \%$ para aumentar o seu conhecimento e $5 \%$ pela influência de terceiros.

Outras motivações impulsionaram a busca pela escola destes sujeitos: recuperar o tempo perdido; manter o emprego e renda diante da necessidade de uma certificação escolar; um "projeto terapêutico-familiar" para o abandono das drogas; o resgate da cidadania por meio de valores como a escola e o trabalho para aqueles que estão em situação de reclusão; o desejo de interar-se com os acontecimentos do cotidiano (ler e compreender os fatos) (CAMPOS, 2014).

No entanto, para o público idoso que retomou os estudos na EJA, as motivações são um pouco diferenciadas: ajudar os netos nas atividades escolares; sair de casa e estabelecer novas amizades; recomendação médica; incentivo dos amigos e familiares; importância, pelo próprio sujeito, da escola na sua vida (CORTES, 2012); a busca pelo acolhimento (CAMPOS, 2014). Outro estudo realizado por Soares (2013) com alunos entre 15 e 69 anos de idade, mostrou que os idosos, em especial, voltaram a estudar motivados pelo desejo de apenas alfabetizar-se (11 idosos), de participar de um grupo (6), de querer ocupar o seu tempo livre (6) e para acompanhar filhos e netos (2), demonstrando que o estabelecimento de relações sociais e sua inserção em um grupo são fatores mais recorrentes frente ao retorno dos idosos aos estudos.

Convergindo com estes resultados, pesquisa de Almeida (2012), com idosos entre 60 e 78 anos de idade, apontou as razões para que estes sujeitos permanecessem na escola: liberdade (de ir e vir); dignidade; bem-estar; aprender a escrever uma simples carta; ler alguns ou todos os livros da Bíblia; desempenhar melhor atividades que já faz; conseguir a carteira de motorista; realizar uma faculdade; comunicar-se; ter mais conhecimento e melhores oportunidades na vida; fazer novas amizades ou simplesmente distrair-se.

Estudo de Pereira (2012), com 10 trabalhadores alunos da EJA, entre 30 e 60 anos de idade, mostrou que estar na escola não representou somente um ganho de conhecimento, mas um resgate da autoestima (uma vez que muitos destes sujeitos estão perto da aposentadoria); a liberdade para dirimir dúvidas e se expor, sem o risco de serem castigados, caso errassem. O orgulho de retomarem os estudos após tantos anos afastados e o fato de poderem contribuir, mais tarde, com seus filhos e netos nas atividades escolares, foi um dos primeiros sentidos para que retomassem os bancos escolares. Além disto, a ascensão profissional foi um dos motivos mencionado. A vergonha de voltar a estudar após 30 anos de idade também foi um elemento que apareceu nas entrevistas.

Algumas das pesquisas também demonstraram importantes mudanças ocorridas após o retorno aos estudos do sujeito adulto da EJA, dentre elas, mais segurança para se comunicar com as pessoas; autoestima resgatada; 
participação na cultura, na sociedade e na produção de conhecimento; melhorias na escrita e na oralidade; novas relações sociais e de amizades; o desejo de continuar estudando (CAMPOS, 2014) e a independência para se deslocar pela cidade (por exemplo, para pegar um ônibus) (SILVA, 2014).

Portanto, pode-se depreender, a partir dos estudos realizados com o público idoso na EJA, que suas expectativas são muito diferentes do público adulto que a busca ou frequenta, tendo em vista as particularidades dessa fase do ciclo de vida. Segundo Coura (2008), as trajetórias biográficas de pessoas com mais de 60 anos que voltam a estudar são bastante semelhantes: origem em famílias bastante humildes e numerosas; necessidade de ajudar no sustento da família desde muito jovens.

As pesquisas também retrataram os motivos pelos quais os sujeitos abandonaram os estudos na EJA. Dentre eles, a pesquisa de Lara (2011) demonstrou que, dos 20 sujeitos entrevistados, $25 \%$ abandonaram os estudos por questões ligadas somente ao trabalho; $20 \%$ por questões envolvendo somente a família; $20 \%$ relacionados ao trabalho e à família; $10 \%$ somente a questões de saúde; $10 \%$ a questões de saúde e trabalho; $10 \%$ a problemas pessoais e $5 \%$ a dificuldades de aprendizagem.

\section{Considerações finais}

O estudo realizado evidenciou que ainda há um número reduzido de produções voltadas ao aluno adulto da EJA, embora tenhamos verificado que houve um incremento do número de produções com este enfoque nos anos de 2012 e 2014, especialmente, envolvendo os alunos idosos nesta modalidade de ensino.

Além disso, as pesquisas com o sujeito adulto da EJA demonstraram que há relativa similaridade dos motivos pelos quais os sujeitos abandonaram os estudos, na idade considerada adequada, e as razões pelas quais retornaram aos bancos escolares. Porém, cada sujeito envolvido no processo de retomada da sua escolarização atribuiu um significado/sentido à retomada dos estudos e à aprendizagem em sua vida, que são reveladas a partir do momento em que as pesquisas e a própria instituição escolar dão voz e protagonismo a estes sujeitos.

Por outro lado, os estudos analisados revelaram a deficiência do sistema público de ensino e as políticas pouco eficazes voltadas à democratização do acesso ao ensino que não caminharam, na mesma intensidade, com políticas que garantam permanência dos sujeitos na escola, dada a necessidade de sobrevivência e a constante luta entre estudar e trabalhar. Entendemos, porém, que este estudo pode não refletir a amplitude da produção sobre a temática dos últimos cinco anos, ao estar restrito a banco de dados específicos e frente à dificuldade de se obter as produções acadêmicas no período de 2010 a 2015 nas bases de dados consultadas. Ademais, a ausência de uniformização nos usos de descritores na área da Educação demandou um maior tempo para se chegar aos resultados desejados. 
Por fim, este trabalho sugere a necessidade de que se produzam pesquisas sobre os sujeitos adultos da EJA em suas especificidades, assim como possam ser verificados os possíveis impactos do processo educativo na vida destes sujeitos, superando a concepção de pesquisa produzida até então a respeito da EJA como uma modalidade compensatória e voltada a um público homogêneo, oriundo de camadas populares.

\section{Referências}

ALMEIDA, Cláudia Elizângela Barbosa dos Santos. Alunos idosos na EJA: a importância da família e dos grupos de convivência no processo de escolarização. 2012. 99f. Dissertação (Mestrado em Educação) - Universidade Católica de Petrópolis, 2012.

Instituto Brasileiro de Informação em Ciência e Tecnologia. IBICT. Biblioteca Digital Brasileira de Teses e Dissertações. BDTD. Disponível em: <http://www.ibict.br/informacao-para-ciencia-tecnologia-e-inovacao\%20/biblioteca-digital-brasileira-de-teses-e-dissertacoesbdtd>. Acesso em: 30 maio 2015.

CALDEIRA, Liliam Cristina. Da escolarização à reinvenção de si: os sentidos da aprendizagem para o aluno da EJA. 2011. $204 \mathrm{f}$. Tese (Doutorado em Educação) - Fundação Universidade Federal de Mato Grosso do Sul, 2011.

CAMPOS, Jaqueline Dinorá Paiva de. Cartografia de vida no trabalho educativo com jovens e adultos: conversas-em-ação. 2014. 72f. Dissertação (Mestrado em Educação) - Universidade Federal do Rio Grande do Sul, 2014.

CARVAlHO, Adenivan Mendes. Memória e identidade do aluno da EJA em relatos autobiográficos. 2014. 172f. Dissertação (Mestrado em Letras) - Universidade Presbiteriana Mackenzie, 2014.

COORDENAÇÃO DE APERFEIÇOAMENTO DE PESSOAL DE NÍVEL SUPERIOR. CAPES. Banco de Teses e Dissertações. Disponível em: <http://www.capes.gov.br/servicos/banco-de-teses>. Acesso em: 23 e 30 mar., 04, 05, 12 e 16 abr. 2015.

CORTES, Roberta Pereira Rodrigues Marini. Sentidos da educação de jovens e adultos na perspectiva do aluno idoso. $2012.101 \mathrm{f}$. Dissertação (Mestrado em Educação) - Universidade Católica de Petrópolis, 2012.

COURA, Isamara Graziela Martins. Entre medos e sonhos nunca é tarde para estudar: a terceira idade na Educação de Jovens e Adultos. ANPED, 16 p. In: REUNIÃO ANUAL DA ANPED, 31., 2008, Caxambu. Anais da ..., 2008.

DIAS, Fernanda Vasconcelos; CARMO, Helen Cristina do; OLIVEIRA, Heli Sabino de; SILVA, Jerry Adriani da; CRUZ, Neilton Castro da; GONZAGA, Yone Maria. Sujeitos de mudanças e mudanças de sujeitos: as especificidades do público da Educação de Jovens e Adultos. In: SOARES, Leôncio (Org.). Educação de Jovens e Adultos: o que revelam as pesquisas. Belo Horizonte: Autêntica Editora, 2011.

HADDAD; Sérgio (Coord.). Educação de Jovens e Adultos no Brasil (1986-1998). Brasília: MEV/Inep/Comped, 2002.

Prefácio. In: SOARES, Leôncio (Org.). Educação de Jovens e Adultos: o que revelam as pesquisas. Belo Horizonte: Autêntica Editora, 2011.

Educação Por Escrito, Porto Alegre, v. 7, n. 1, p. 59-73, jan.-jun. 2016 
INSTITUTO NACIONAL DE ESTUDOS E PESQUISAS EDUCACIONAIS ANÍSIO TEIXEIRA, INEP. Thesaurus Brasileiro da Educação. Disponível em: <http://pergamum.inep.gov.br/pergamum/biblioteca/pesquisa_thesauro.php?resolution2=1024_1>. Acesso em: 30 mar. 2015.

LARA, Pedro José de. Educação de Jovens e Adultos: perspectivas e evasão no município de Cáceres-MT. 2011. 98f. Dissertação (Mestrado em Educação) - Universidade Oeste Paulista, 2011.

MORAES, Roque. Análise de Conteúdo. Revista Educação, Porto Alegre, v. 22, n. 37, p. 7-32, 1999.

MOROSINI; Marília Costa; FERNANDES, Cleoni Maria Barboza. Estado do Conhecimento: conceitos, finalidades e interlocuções. Educação Por Escrito, Porto Alegre, v. 5, n. 2, p. 154-164, jul.-dez. 2014.

OLIVEIRA, Eliana de; ENS, Romilda Teodora; ANDRADE, Daniela B. S. Freire; MUSSIS, Carlo Ralph de. Análise de Conteúdo e pesquisa na área da educação. Revista Diálogo Educacional, Curitiba, v. 4, n. 9, p. 11-27, maio/ago. 2003.

PEREIRA, Sheyla Aparecida. A construção da escrita por alunos adultos: análise de processos de ensino com base na Teoria Histórico Cultural do Desenvolvimento. 2012. 111f. Dissertação (Mestrado em Educação) - Universidade Regional de Blumenau, 2012.

ROMANOWSKI, Joana Paulina; ENS, Romilda Teodora. As pesquisas denominadas do tipo "Estado da Arte” em Educação. Diálogo Educ., Curitiba, v. 6, n.19, p. 37-50, set./dez. 2006.

SILVA, Rafael Domingues da. Desvelando histórias de alunas (os) trabalhadoras (es) do pmea: indícios para construção de uma EJA democrática e dialógica. 2014. 211f. Dissertação (Mestrado em Educação) - Universidade Federal de Uberlândia, 2014.

SOARES, Andréia Cristina da Silva. O Diurno na educação de jovens e adultos: quem são esses sujeitos? 2013. 131f. Dissertação (Mestrado em Educação) - Universidade do Estado do Rio de Janeiro, 2013.

SOARES, Leôncio (Org.). Educação de Jovens e Adultos: o que revelam as pesquisas. Belo Horizonte: Autêntica Editora, 2011.

SOARES, Leôncio; SILVA, Fernanda Rodrigues; FERREIRA, Luiz Olavo Fonseca. A pesquisa em Educação de Jovens e Adultos: um olhar retrospectivo sobre a produção do período de 1998 a 2008. In: SOARES, Leôncio (Org.). Educação de Jovens e Adultos: o que revelam as pesquisas. Belo Horizonte: Autêntica Editora, 2011.

Recebido em: junho/2015

Aceito em: dezembro/2015

Endereço para correspondência:

Fernanda de Brito Kulmann Conzatti

Rua Visconde de Pelotas, 95/412

91030-530 Porto Alegre, RS, Brasil

<nandakulmann@gmail.com> 